\title{
Social Mobility Attributions in East Asian and Pacific Cultures: Power Distance and Individualism as Moderators of Self-Attribution Bias
}

\author{
Melissa Lopez Reyes \\ Department of Psychology, De La Salle University, Manila, Philippines
}

\begin{abstract}
S elf-attribution bias operates in social mobility attributions, with positive circumstances triggering $\checkmark$ individualist attributions (attributed to one's merits) and negative circumstances triggering structural attributions (attributed to one's race, religion, sex, social connections). Analyses of East Asian and Pacific data of the International Social Survey Programme's Social Inequality Module show that perceived social inequality (PSI) leads to structural attributions, while high subjective social position (SSP) leads to individualist attributions. Cultural contexts, however, support or temper self-attribution bias, thus modifying the effects of PSI and SSP. Cross-level interactions show that the effect of PSI on structural attributions is larger in small power-distance countries, while the effect of SSP on individualist attributions is larger in countries with small power distance, high individualism, and low country average for SSP. That a small power distance strengthens the effects of PSI on structural attributions and of SSP on individualist attributions suggests contrasting scenarios, where disadvantaged groups devalue their competencies for mobility, while privileged groups believe themselves deserving of better outcomes. The contextdependency of the SSP effect suggests the modifiability of individualist attributions. These results help explain why mobility attribution profiles of Australia and New Zealand differ from those of China, Japan, the Philippines, South Korea, and Taiwan.
\end{abstract}

Keywords: East Asia and the Pacific, individualism, power distance, self-attribution bias, social mobility

Upward social mobility results from the confluence of hard work and social affordances. In countries with marked social inequality, the better-off sectors have access to affordances and the disadvantaged sectors struggle to attain social mobility on one's merits (Breen, 1997). Notwithstanding constraints imposed by social inequality and low social class, individuals' upward mobility may either be facilitated or constrained by the causal attributions they make. To some extent, persons attribute mobility to personal merits (individualist attributions) or to socioeconomic or demographic profile (structural attributions), including race, religion, gender, and social connections (Kluegel, 1987; Taylor \& Merino, 2011).

\section{Self-Attribution Bias in Mobility Attributions}

Kelley's (1973) classic covariation analysis is the process of attributing the cause of an outcome to surrounding events and circumstances. Thus, ascribed causes of poverty, such as laziness and unemployment, arise from available infor- mation about the person and the situation, such as job performance and unemployment rate (Weiner, Osborne, \& Rudolph, 2010). As structural attributions are in the external locus, observed or perceived characteristics of society are a relevant covariate. Indeed, people are sensitive to country conditions when deciding how social and demographic factors contribute to upward mobility (Fong, 2001). Likewise, as individualist attributions are in the internal locus, perceived characteristics of self are a relevant covariate. Indeed, people assess the actor's qualities when deciding whether ability and hard work contributed to success (Weiner, 2008).

The premise of this study is that self-attribution bias drives the direction of the relationships between the covariates and attributions of mobility. Self-attribution bias refers to people's tendency to attribute positive events to internal factors and negative events to external factors (Heider, 1958; Mezulis, Abramson, Hyde, \& Hankin, 2004). Also called self-serving attribution bias,

Address for correspondence: Melissa Lopez Reyes, Department of Psychology, De La Salle University, 2401 Taft Avenue, Manila, 0922 Philippines. Email: melissa.reyes@dlsu.edu.ph 
self-attribution bias is an adaptive mechanism for protecting self-esteem (Duval \& Silvia, 2002). For example, self-attribution bias enables both lower and higher social classes to reckon with their status: high-status individuals impute success to their own work, thus justifying their status, while low-status individuals deflect from their lesser financial success by ascribing it to structural factors (Gugushvili, 2016; Kraus, Piff, \& Keltner, 2009).

Self-attribution bias has been found to vary across different ages, cultures, and depression states; still, its predictors need to be precisely identified (Mezulis et al., 2004). Major (1994), for instance, theorises that being in a position of advantage or disadvantage predicts self-attribution bias: disadvantaged individuals feel less deserving of better outcomes and advantaged individuals feel entitled to better outcomes. Consistent both with the self-attribution bias and Major's (1994) supposition are this study's claims that if upward mobility becomes daunting because of social inequality, then individuals would make structural attributions; and, if a high social position is regarded as a mark of success, then high-status individuals would make individualist attributions.

\section{Structural Attributions and Perceived Social Inequality}

Inequality is negatively associated with intergenerational mobility (Sakamoto, Rarick, Woo, \& Wang, 2014), providing a factual basis for the hypothesised relationship between perceived social inequality (PSI) and structural attributions. This hypothesis also has a psychological basis. Associated with PSI are negative events that trigger self-attribution bias. For one, social inequality engenders social exclusion and lack of social capital, as have been experienced by the poor in postcommunist countries (Letki \& Mierina, 2015). The marginalisation experienced by groups of Filipino Muslims underlies their attributing social conflicts to structural problems (Montiel \& Macapagal, 2006). With negative events as correlates of PSI, people tend to attribute social mobility to structural factors.

Pertinent to the hypothesised link between PSI and structural attributions is the finding that those who keenly perceive social inequality tend to be concerned about income disparities and redistribution (Bjørnskov, Dreher, Fischer, Schnellenbach, \& Gehring, 2013; Kerr, 2014). Indeed, individuals have acknowledged that it is their exposure to inequality and poverty that led them to be involved in anti-poverty initiatives (Cattell, 2001). That PSI leads people to support initiatives to lessen inequality suggests that PSI is a felt negative event. Consistent with the self-attribution bias, downward social mobility concomitant to PSI will be attributed more to structural factors.

Still another reason why PSI is a felt negative event that triggers self-attribution bias is suggested by findings that PSI is correlated with being dissociated or lacking bonds with other individuals or groups. A study of so- cial networks in a poor area of London indicates that those who lack positive reference groups tend to see other poor individuals as different, as competitors, and as undeserving of social benefits (Cattell, 2001). Germans across social classes report that poverty and ostentatious wealth are both deviations from a universally acceptable standard and produce social disintegration and segregation of 'life-worlds' (Sachweh, 2012). In contrast, experiencing commonality with other groups develops positive regard, as shown in an experiment where commonality-focused interactions with students from a higher status university led participants to view social hierarchy as legitimate and to hold off imputing negative treatments to discrimination (Saguy \& Chernyak-Hai, 2012).

In summary, individuals with high PSI are more sensitive to its negative consequences and tend to attribute upward mobility to privilege. Thus, it is hypothesised that H1a: Greater PSI predicts more structural attributions of social mobility.

\section{Individualist Attributions and Subjective Social Position}

Social mobility is difficult to attain among lower social classes (Neckerman \& Torche, 2007). In England, for example, the effect of social origins on mobility, unmediated by educational attainment, has been found to be consistently large (Gugushvili, Bukodi, \& Goldthorpe, 2017). One factor that limits social mobility among the lower social classes is their limited access to social capital and social networks (Billet, 2011; Lew, 2010; Putnam, 1993). Social-psychological correlates of poverty, such as lessened cognitive and motivational resources, also hinder the poor from achieving upward mobility despite hard work and effort (Sakamoto et al., 2014). In contrast, the social capital and networks of higher social classes provide the wherewithal for hard work and effort to translate to success. Given the assumption of self-attribution bias, individuals from higher social classes will make more individualist attributions than individuals from lower social classes.

Not only objective social position but also subjective social position (SSP) is possibly associated with individualist attributions. SSP reflects one's identification with the claimed social position borne out of socialisation into the community (Mead, 1934). Persons who identify with lower social classes would have been socialised into limited social capital and opportunities. They may even have developed internalised classism, seeing themselves as less competent than the higher classes (Russell, 1996). SSP also has psychological consequences among those who identify with higher social classes as they will likely find downward mobility aversive (called 'loss aversion') and will be motivated to avoid it (Gugushvili et al., 2017). Both low and high SSPs thus trigger self-attribution bias: internalised classism of those with low SSP is less likely to result in individualist attributions, while the motivation triggered by loss aversion of those with high SSP is more likely to result in individualist attributions. 
There is empirical support for the hypothesised selfattribution bias. Those who have experienced substantial upward social mobility are more likely to make individualist attributions of poverty (e.g., laziness, lack of will) and less likely to make structural attributions (e.g., injustice in society; Gugushvili, 2016). In contrast, lower-class individuals tend to make more contextual attributions of social and economic outcomes and fewer dispositional attributions (Kraus, Piff, \& Keltner, 2009). It is hypothesised that H1b: Higher SSP predicts more individualist attributions of social mobility.

The current study further aims to establish societal and cultural contexts that determine to what extent people's attributions are based on inequality and social status perceptions. Similar context effects have been established in country studies on poverty or mobility attributions (e.g., Hunt, 1996; Gugushvili, 2016).

This study tests hypotheses of cross-level interactions between country variables and PSI/SSP to support claims of differing cultural patterns of attributions (Choi, Nisbett, \& Norenzayan, 1999; Hong, Morris, Chiu, \& Benet-Martinez, 2000). It explores the supposition that a cultural-level variable may underscore or de-emphasise an individual-level variable so that its effect is weakened or heightened in some cultures more than in others. A country-level variable that supports self-attribution bias will strengthen the effects of PSI/SSP on attributions, while a country-level variable that counteracts self-attribution bias will weaken these effects.

\section{Does Country-Level PSI Moderate the Effect of PSI on Structural Attributions?}

While PSI is an individual-level variable, it can be conceptualised as a country-level variable reflecting the prevailing inequality perception. Analytically, a country-level variable is the average of the corresponding individual-level scores in a country (Fischer, 2009). This study is concerned with how the effect of PSI on structural attributions varies as a function of country-level PSI (C-PSI).

A country's inequality, by itself, has been shown to be a moderator: individuals' high fairness perceptions have positive effects on happiness and the effects are stronger amid high income inequality or low social mobility (Bjørnskov et al., 2013). C-PSI may have analogous moderating effects. It reflects a part of a culture's shared meaning system (Fischer, 2009) and has the characteristic of interobjectivity, or the understanding of social reality formed from individuals' socialisation into a culture's collective (Moghaddam, 2003, 2010). A high C-PSI reflects the saliency of inequality in people's shared meaning system or interobjectivity. Such saliency validates or confirms high PSIs, and furthermore that high PSIs translate to structural attributions, but low C-PSIs do not produce the same saliency effect. It is hypothesised that $\mathrm{H} 2 \mathrm{a}$ : A high C-PSI strengthens the positive effect of PSI on structural attributions.

\section{Does Country-Level SSP Moderate the Effect of SSP on Individualist Attributions?}

Countries differ in income distribution. Some countries have a majority of the population in the lower socioeconomic rungs and some countries have a sizeable middle class. This study concerns how the effect of SSP on individualist attributions varies as a function of country-level SSP (C-SSP).

Major (1994) theorises that individuals engage in social comparison when determining the range of achievement outcomes (e.g., promotion) that could be achieved through certain situations (e.g., academic attainment). People conclude covariations between achievement outcomes and their sources based on multiple standards, including outcomes achieved by self or by others, as well as pertinent societal trends. For example, people form covariations between entitlement and attribution, with internally caused disparities between individuals perceived as more legitimate than externally caused disparities. Major (1994) furthermore claims a cognitive bias in people's social comparison that inhibits awareness of disadvantage.

Social comparison is likely at play when assessing one's social position (Festinger, 1954). A low C-SSP provides a marked contrast between high-SSP individuals and society's standard, but provides only a small, even insignificant contrast, between low-SSP individuals and society's standard. This difference between either end of SSP would buttress the hypothesised positive relationship at lower C-SSP. On the other hand, a high C-SSP would not provide a marked contrast to high SSP; it would provide a marked contrast to low SSP, albeit this social comparison will not have a self-enhancing effect by the tenet of attribution theory. With such differing patterns between low and high C-SSP, it is hypothesised that H2b: A low C-SSP strengthens the effect of SSP on individualist attributions.

\section{Does Power Distance Moderate the Effects of PSI and SSP on Attributions?}

Power distance is a potential moderator of the effects of inequality and status perceptions on attributions to the extent that people incorporate it in their covariation analysis (Kelley, 1973), thus heightening a negative or positive outcome and inducing greater self-attribution bias.

Hofstede (2001; Hofstede, Hofstede, \& Minkow, 2010) defines power distance as a culture's acceptance and expectation of inequality. In small power-distance cultures, power is diffused and opportunities are accessible to many sectors. The cultural mindset is that social mobility could be had through one's efforts and hard work. In large power-distance cultures, power structures are unquestioned and opportunities are contained in a few sectors. The cultural mindset is that social mobility is for those with social, economic, and demographic advantage.

Hegtvedt and Johnson (2000) claim that endorsement of a perceived unjust distribution lessens the severity of the injustice. Similarly, the endorsement of inequality in 
large power-distance cultures legitimises externally caused disparities among individuals and deflects the negative effects of inequality in people's shared meaning system. The self-attribution bias of attributing mobility to structural factors is thus tempered in large power-distance cultures, and high PSIs would not lead as much to structural attributions.

Moreover, the endorsement of inequality in large power-distance cultures deflects the perception that a high social position can be had through one's merits. Even as individuals recognise their high social position, the cultural mindset that social structures provide advantage to well-positioned sectors tempers the self-attribution bias of attributing mobility to internal factors. Thus, high SSPs would not lead as much to individualist attributions. It is hypothesised that H3a: A country's large power distance weakens the effect of PSI on structural attributions; and H3b: A country's large power distance weakens the effect of SSP on individualist attributions.

\section{Does Individualism Moderate the Effects of PSI and SSP on Attributions?}

Individualism is another potential moderator of the effects of inequality and status perceptions on attributions. Individualist cultures value personal choice and selfdetermination (Vinken, 2006). While social relations can be personally meaningful, social ties do not define a person's identity and life goals. People tend to look after themselves, with little expectation to support or receive support from others (Hofstede, 2001; Hofstede et al., 2010). In collectivist cultures, persons' identities are crafted around an in-group with whom persons have formed lifelong ties (Vinken, 2006). The in-group's interests prevail over the individual's and members are expected to fend for each other (Hofstede, 2001; Hofstede et al., 2010).

Individualist cultures highlight the distinction between individuals and their social surroundings while collectivist cultures blur it (Bochner \& Hesketh, 1994). In individualist cultures, behaviours and events are referenced on people's thoughts and actions, while in collectivist cultures, these are referenced on others (Markus \& Kitayama, 1991). With the premium placed by individualist cultures on the person, individualist attributions likely figure more substantively in persons' covariation analysis and the bias of attributing the negative event of PSI on external factors is then tempered, while the bias of attributing the positive event of high SSP on internal factors is strengthened. With the premium placed by a collectivist culture on the in-group, structural attributions likely figure more substantively than individualist attributions in persons' covariation analysis and the bias of attributing the negative event of PSI on external factors is strengthened, while the bias of attributing the positive event of high SSP on internal factors is weakened. It is hypothesised that H4a: A country's individualism weakens the effect of PSI on structural attributions; and H4b: A country's in- dividualism strengthens the effect of SSP on individualist attributions.

\section{East Asian and Pacific Cultures as Context of the Current Research}

This study's hypotheses are examined in East Asian and Pacific countries included in the 2009 Social Inequality Survey of the International Social Survey Programme (ISSP Research Group, 2012): Australia, China, Japan, New Zealand, the Philippines, South Korea, and Taiwan.

Variations in power distance exist in this region. Australia and New Zealand are high-income economies and, with their democratic orientation, convey a small power distance. Japan, South Korea, and Taiwan are high-income economies with a smaller power distance than China, an upper-middle-income economy, and the Philippines, a lower-middle-income economy (Hofstede, 1983, 2001; World Bank, 2017). Japan, South Korea, and Taiwan have invested heavily in human capital (e.g., education), attaining a more egalitarian income distribution, while Southeast Asian countries have experienced less educational and economic progress (Booth, 1999; Yun, 1994). The Confucian culture of China, Japan, and South Korea sees stability as rooted in the unequal but respectful and filial social relationships (Hofstede \& Bond, 1988). In Japan and South Korea, however, citizen sovereignty has been respected by government, including the right to be critical of government (Kim, 2010).

It is also of interest to examine individualism in this region. Asian cultures see the self as being encompassed by the in-group (Triandis, 1989). With intricate and expanded social networks, East Asian cultures value loyalty towards the group, maintenance of reciprocal relations, and cooperation towards group goals (Putnam, 1993; Vinken, 2006). The Western cultures of Australia and New Zealand, on the other hand, are known for individualist and meritocratic values. Westerners have greater self-concept clarity (Campbell et al., 1996) and regard the self as central, coherent, and consistent (Tsukamoto, Holland, Haslam, Karasawa, \& Kashima, 2015).

\section{Significance of the Study}

This study is important in a number of respects. First, it examines inequality and social position from a social-psychological level, showing how inequality and status perceptions bear on mobility beliefs. Such beliefs in turn shape how young people will navigate their way towards social mobility (Clemente, Daganzo, Bernardo, \& Pangan, 2017; Shane \& Heckhausen, 2013). Second, while attributions have largely been examined in general, culture-free situations (Kelley \& Michela, 1980), this study situates attributions in the social-cultural context of a particular geographical region, thus addressing the need to specify economic and cultural factors that underlie 
Table 1

Respondents' Demographic Characteristics per Country

\begin{tabular}{|c|c|c|c|c|c|c|}
\hline Country & $\begin{array}{l}\text { Sample } \\
\text { size }\end{array}$ & $\begin{array}{l}\text { Percentage } \\
\text { retained from the } \\
\text { original sample }\end{array}$ & $\begin{array}{l}\text { Percentage } \\
\text { female }\end{array}$ & Age $M(S D)$ & $\begin{array}{l}\text { Percentage } \\
\text { with college } \\
\text { degree }\end{array}$ & $\begin{array}{l}\text { Percentage who have } \\
\text { completed secondary } \\
\text { schooling* }\end{array}$ \\
\hline Australia & 1385 & $91 \%$ & $57 \%$ & $52.2(16.6)$ & $29 \%$ & $50 \%$ \\
\hline China & 2938 & $98 \%$ & $52 \%$ & $42.9(14.1)$ & $6 \%$ & $32 \%$ \\
\hline Japan & 1068 & $82 \%$ & $52 \%$ & 48.5 (17.3) & $23 \%$ & $60 \%$ \\
\hline New Zealand & 889 & $95 \%$ & $55 \%$ & $50.1(16.8)$ & $26 \%$ & $50 \%$ \\
\hline Philippines & 1190 & $99 \%$ & $50 \%$ & $42.4(16.1)$ & $12 \%$ & $41 \%$ \\
\hline South Korea & 1586 & $99 \%$ & $52 \%$ & $43.4(15.2)$ & $26 \%$ & $53 \%$ \\
\hline Taiwan & 2000 & $99 \%$ & $48 \%$ & 44.5 (16.4) & $20 \%$ & $44 \%$ \\
\hline Total & 11056 & $95 \%$ & $52 \%$ & $45.5(16.1)$ & $18 \%$ & $44 \%$ \\
\hline
\end{tabular}

Note: *Some may have additional qualifications.

country differences in beliefs (Taras, Kirkman, \& Stell, 2010). Third, the multilevel analysis used in this study enables the examination of cross-level interactions between individual-level predictors of mobility and country-level societal and cultural moderators. Country-level variables have been shown to predict attributions (e.g., Morris \& Peng, 1994), but this study underscores the role of culture in providing the social context that magnifies, tempers, or removes the effects of individual-level predictors.

\section{Method}

\section{Participants}

The data analysed were from the 2009 Social Inequality IV Cross-Country Survey of the International Social Survey Programme (GESIS Leibniz Institute for the Social Sciences, 2012; ISSP Research Group, 2012). The data analysed were restricted to those from Australia, China, Japan, New Zealand, the Philippines, South Korea, and Taiwan $(n=11,056)$. Only respondents with data on at least half of the items constituting each measure were included. The included respondents constituted $95 \%$ of the original sample. At least $90 \%$ of a country's sample was retained, with the exception of Japan, where only $82 \%$ was retained.

Table 1 shows the sample size and respondents' demographic characteristics per country. The percentage of females for the entire sample was $52 \%$ (range $48-57 \%$ across countries). The mean age for the entire sample was 45.5 (range 42.4-52.2 across countries). The percentage of respondents with a college degree was 18\% (range 6$29 \%$ ). The percentage of respondents who had completed secondary schooling, with some having additional qualifications, was $44 \%$ (range 32-60\%).

\section{Measures}

Except for individualism and power distance, the measures described below were part of the survey instrument for the ISSP 2009 Social Inequality Module. Item descriptions and the quoted item phrases were obtained from the documentation of the final questionnaire (ISSP, 2008).

Structural attributions refer to the following categories: (a) demographic profile ('a person's race and reli- gion, being born a man or a woman'), (b) family ('coming from a wealthy family, having well-educated parents'), and (c) social connections ('knowing the right people, having political connections'). Respondents indicated how important they thought an item was for getting ahead in life. Responses were scored from 5 (essential) to 1 (not important at all).

Scores were averaged within each category and these were then averaged to obtain a measure of structural attribution (so that equal weights were assigned to the categories). The Cronbach's alphas for demographic profile, family, and social connections were .77 (three items), .67 (two items), and .66 (two items) respectively. The Cronbach's alpha for all the items was .78.

Individualist attributions refer to a person's own work and efforts: 'having a good education, having ambition, and hard work'. The question and response options were the same as for structural attributions. Item scores were averaged to obtain a measure of individualist attributions. Cronbach's alpha $=.61$ (three items).

In the questionnaire, the individualist and structural attributions items were included in one list.

Perceived social inequality was measured in terms of the following categories: (a) unequal access to education ('only students from the best secondary schools have a good chance to obtain a university education; only the rich can afford the costs of attending university; people have the same chances to enter university regardless of gender, ethnicity, or social background' [reverse-scored]); (b) extent of social class conflict ('between poor people and rich people, between the working class and the middle class, between management and workers, between people at the top of society and people at the bottom'); and (c) unjustness of salaries of high-level professionals ('doctor in general practice, chairman of a large national corporation, cabinet minister in the government').

For unequal-access-to-education items, respondents indicated extent of agreement from strongly agree (5) to strongly disagree (1). For extent-of-class-conflict items, respondents assessed extent of conflict between groups from very strong conflict (4) to there are no conflicts (1). For unjustness-of-salaries items, respondents reported actual and perceived appropriate salaries in separate lists. A score 
of 3 was given if the actual was larger than the perceived appropriate salary, 2 if the actual was equal to the perceived, and 1 if the actual was smaller than the perceived.

After converting scales to a uniform 1-to-3 scale, scores were averaged within each category and these were then averaged to have a measure of perceived social inequality (so that equal weights were assigned to the categories). The Cronbach's alphas for unequal access to education, class conflicts, and unjustness of salaries were .49 (3 items), .82 (4 items), and .55 (3 items) respectively. The Cronbach's alpha for all the items was .51.

Subjective social position. The first question read: 'In our society there are groups which tend to be towards the top and groups which tend to be towards the bottom. Below is a scale that runs from top to bottom. Where would you put yourself now on this scale?' The response options were 10 to 1 , with 10 labelled TOP and 1 labelled BOTTOM. The second question read: 'Most people see themselves as belonging to a particular class. Please tell me which social class would you say you belong to?' Response options were: lower class, working class, lower middle class, middle class, upper middle class, and upper class; these were scored from 1 to 6 respectively. For purposes of scale uniformity, the 1-to-10 scale of the first question was converted to the 1-to- 6 scale of the second question. The mean score of the two questions was used as the measure. Cronbach's alpha was .71.

Individualism and power distance. Country scores for individualism and power distance were obtained from the studies of Hofstede and colleagues (Hofstede, 1983, 2001; Hofstede et al., 2010) as reported in the website https://geert-hofstede.com/countries.html. The scores were on a 0 -to- 100 scale with higher scores reflecting more of the construct being measured.

The measures and country scores originated from the survey data of more than 100,000 IBM ${ }^{\circledR}$ employees worldwide (Hofstede, 2001). Individualism and power distance were two of the cultural dimensions that Hosftede derived from both theoretical argumentation and factor analyses (Hofstede, 1983, 2001). As listed in Orr and Hauser (2008), sample items for individualism were: 'I would not support my work group if I felt they were wrong' and 'It is better to work in a group than alone' (15 items). Sample items for power distance were 'I would never argue with my supervisor' and 'Employees should participate in the decisions made by management' (17 items).

As explained by Hofstede $(1983,2011)$ and emphasised by Oyserman, Coon, and Kemmelmeier (2002), the cultural dimensions are to be used at the country level and not at the individual level, as the former cannot directly explain individual behaviour and the latter presents a theoretically different issue. In fact, individual-level correlational and factor analyses did not reveal clear patterns, but corresponding country-level analyses did (Hofstede, 2011). Consistent with the country-level perspective, cross-cultural research has used Hofstede's country scores in country-level analyses (e.g., Johnson, Kulesa, Cho, \& Shavitt, 2005; Matsumoto et al., 2008; Robert, Probst, Martocchio, Drasgow, \& Laler, 2000).

Hofstede's country scores on individualism correlated positively with country scores on the corresponding scale of the Work-Values Survey (three replications) and with Triandis' expert ratings of countries' individualism (median correlation of .70; Schimmack, Oishi, \& Diener, 2005). Hofstede's country scores on individualism and power distance also correlated substantively on the 'practice' or 'as is' scores on collectivism and power distance of the GLOBE Project data (Global Leadership and Organizational Behavior Effectiveness, 2004).

\section{Results}

Correlations among individual-level variables and among country-level variables are shown in Tables 2 and 3 respectively. Presented in Table 4 are the countries' individualism and power distance scores, C-PSI, and C-SSP; gross domestic product (GDP) per capita and GINI indices (as a measure of income inequality) are also presented.

\section{Perceived Social Inequality Predicting Structural Attributions}

The hypothesised cross-level interactions between country-level moderators and individual-level predictors necessitated multilevel analysis. Multilevel analysis through hierarchical linear modelling (Raudenbush \& Bryk, 2002) was conducted with structural attributions as an outcome variable and PSI as the individual-level predictor of interest. Age, gender (female coded 0, male coded 1), educational attainment, and SSP were included as individual-level predictors to account and control for their effects. Educational attainment was quantified from 1 to 6 to denote, respectively: 'no formal qualification; lowest formal qualification; above lowest qualification; higher secondary completed; above higher secondary level, other qualification; and university degree completed'. GDP per capita and GINI index were included as country-level predictors to account and for their effects. Consistent with the moderating hypotheses, PSI was made to interact with individualism, power distance, and C-PSI.

Individual-level variables, except gender, were centred around the country mean; country-level variables were centred around the grand mean. The individuallevel model intercept was specified as random while the other coefficients (slopes) were specified as fixed. The full maximum likelihood model of estimation was used.

The individual-level variance estimate was .36, while the country-level variance estimate was .03. The latter was significantly different from zero, $\chi^{2}(4)=561.04, p<$ .001 . The intraclass correlation coefficient was .08, that is, $8 \%$ of the variance in structural attributions was due to country-level variations, specifically, the interactions involving country-level moderators.

Table 5 indicates, for the mixed model, the estimated regression coefficients and their standard errors 
Table 2

Correlations Among Individual-Level Variables

\begin{tabular}{|c|c|c|c|c|c|c|c|c|c|}
\hline \multicolumn{2}{|c|}{ Variable } & \multirow{2}{*}{$\frac{M}{45.50}$} & \multirow{2}{*}{$\frac{S D}{16.12}$} & \multirow[t]{2}{*}{1} & \multirow[t]{2}{*}{2} & \multirow[t]{2}{*}{3} & \multirow[t]{2}{*}{4} & \multirow[t]{2}{*}{5} & \multirow[t]{2}{*}{6} \\
\hline 1 & Age & & & & & & & & \\
\hline 2 & Educational attainment & 3.91 & 1.51 & $-.30 *$ & & & & & \\
\hline 3 & Structural attributions & 2.90 & .76 & $-.11^{*}$ & $-.16^{*}$ & & & & \\
\hline 4 & Individualist attributions & 4.07 & .63 & $-.08^{*}$ & $.06^{*}$ & $.31 *$ & & & \\
\hline 5 & Perceived social inequality & 2.02 & .32 & $-.09 *$ & .00 & $.26^{*}$ & $.04^{*}$ & & \\
\hline 6 & Subjective social position & 3.07 & .98 & $-.12^{*}$ & $.36 *$ & $-.16^{*}$ & $.06 *$ & $-.11^{*}$ & \\
\hline
\end{tabular}

\section{Table 3}

Correlations Among Country-Level Variables

\begin{tabular}{llrrrrrr}
\hline Variable & $M$ & $S D$ & 1 & 2 & 3 & 4 \\
\hline 1 & Individualism & 43.14 & 30.18 & & & & \\
2 & Power distance & 57.71 & 24.42 & -.75 & & & \\
3 & Country mean for perceived social inequality & 2.00 & .15 & -.38 & .11 & & \\
4 & Country mean for subjective social position & 3.17 & .34 & $.91^{* *}$ & $-.87^{*}$ & -.10 & \\
5 & GDP per capita & 20054.10 & 17560.72 & $.77^{*}$ & -.74 & -.49 & .67 \\
6 & GINI Index & 37.53 & 4.83 & -.54 & $.77^{*}$ & -.10 & $-.76^{*}$ \\
\hline
\end{tabular}

Note: ${ }^{*} p<.05,{ }^{* *} p<.01$.

Table 4

Country Profiles on Country-Level Variables

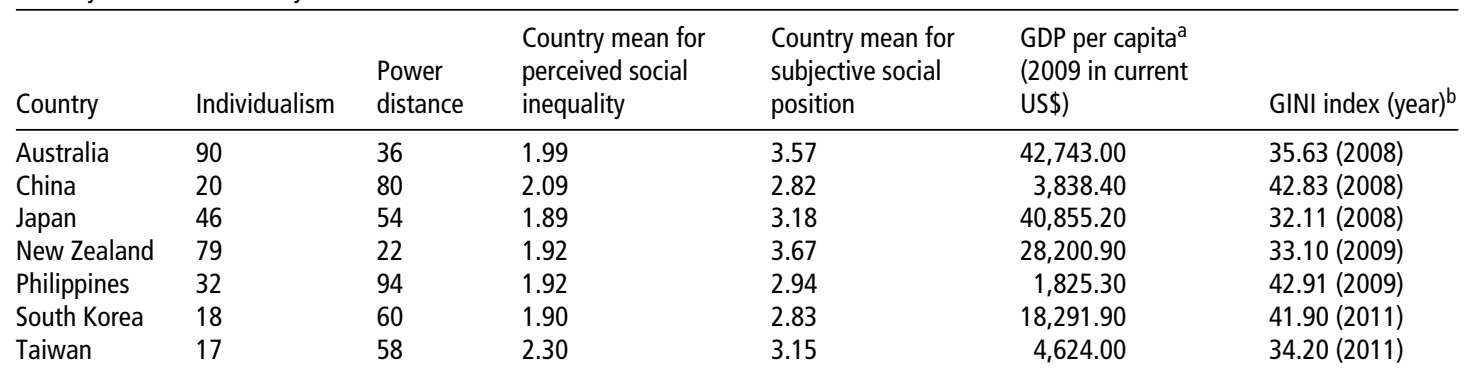

Note: a GDP PER CAPITA is for 2009, the year the ISSP Social Inequality Module was conducted. GDP per capita of Taiwan (4th quarter of 2009) was obtained from Republic of China (Taiwan) Statistical Bureau (2017). GDP per capita of the other countries were obtained from the World Bank national accounts data (2017). ${ }^{b}$ GINI index reported is for the year closest to 2009 when the GINI index was available. GINI indices of Australia, China, Japan, and the Philippines were obtained from the World Bank national accounts data (2017). GINI indices for South Korea and Taiwan were obtained from NationMaster (2017). GINI index for New Zealand was obtained from Perry (2013).

\section{Table 5}

Model With Structural Attributions as Outcome Variable

\begin{tabular}{|c|c|c|c|c|c|c|}
\hline Predictors & $B$ & $S E$ & $t$ & $d f$ & $p$ & $95 \% \mathrm{Cl}$ for $B$ \\
\hline Intercept & 2.7520 & .0629 & 43.76 & 4 & $<.001$ & {$[2.6287,2.8753]$} \\
\hline \multicolumn{7}{|l|}{ Control variables } \\
\hline Gender & .0138 & .0115 & 1.20 & 11041 & .23 & {$[-.0087, .0363]$} \\
\hline Age & .0001 & .0004 & .33 & 11041 & .74 & {$[-.0007, .0009]$} \\
\hline Educational attainment & .0026 & .0046 & .56 & 11041 & .57 & {$[-.0064, .0116]$} \\
\hline Subjective social position & -.0070 & .0065 & -1.07 & 11041 & .286 & {$[-.0197, .0057]$} \\
\hline GDP per capita & -.0000 & .0000 & -1.80 & 4 & .15 & {$[.0000, .0000]$} \\
\hline GINI index & .0685 & .0185 & 3.71 & 4 & .02 & {$[.0322, .1048]$} \\
\hline \multicolumn{7}{|c|}{ Hypothesised individual-level predictor } \\
\hline Perceived social inequality & .4044 & .0208 & 19.42 & 11041 & $<.001$ & {$[.3636, .4452]$} \\
\hline \multicolumn{7}{|c|}{ Interaction of country-level variables with perceived social inequality (PSI) } \\
\hline Individualism $\times$ PSI & .0016 & .0012 & 1.35 & 11041 & .18 & {$[-.0008, .0040]$} \\
\hline Power distance $\times$ PSI & -.0030 & .0014 & -2.1 & 11041 & .04 & {$[-.0057,-.0003]$} \\
\hline Country mean-PSI $\times$ PSI & -.0779 & .1652 & -.47 & 11041 & .64 & {$[-.4017, .2459]$} \\
\hline
\end{tabular}




\begin{tabular}{|c|c|c|c|c|c|c|}
\hline \multicolumn{7}{|c|}{$\begin{array}{l}\text { Table } 6 \\
\text { Model With Individualist Attributions as Outcome Variable }\end{array}$} \\
\hline Predictors & $B$ & $S E$ & $t$ & $d f$ & $p$ & $95 \% \mathrm{Cl}$ for $B$ \\
\hline Intercept & 4.0500 & .1003 & 40.38 & 4 & $<.001$ & {$[3.8534,4.2466]$} \\
\hline \multicolumn{7}{|l|}{ Control variables } \\
\hline Gender & .0069 & .0113 & .61 & 11041 & .55 & {$[-.0152, .0290]$} \\
\hline Age & -.0009 & .0004 & -2.45 & 11041 & .01 & {$[-.0017,-.0001]$} \\
\hline Educational attainment & .0415 & .0045 & 9.20 & 11041 & $<.001$ & {$[.0327, .0503]$} \\
\hline Perceived social inequality & .1045 & .0201 & 5.19 & 11041 & $<.001$ & {$[.0651, .1439]$} \\
\hline GDP per capita & -.0000 & .0000 & -.51 & 4 & .64 & {$[.0000, .0000]$} \\
\hline GINI index & .0150 & .0300 & .51 & 4 & .64 & {$[-.0438, .0738]$} \\
\hline \multicolumn{7}{|c|}{ Hypothesised individual-level predictor } \\
\hline Subjective social position (SSP) & .0328 & .0070 & 4.75 & 11041 & .01 & {$[.0191, .0465]$} \\
\hline \multicolumn{7}{|c|}{ Interaction of country-level variables with subjective social position (SSP) } \\
\hline Individualism $\times$ SSP & .0014 & .0006 & 2.45 & 11041 & .01 & {$[.0002, .0026]$} \\
\hline Power distance $\times$ SSP & -.0017 & .0005 & -3.33 & 11041 & $<.001$ & {$[-.0027,-.0007]$} \\
\hline Country mean-SSP $\times$ SSP & -.1674 & .0613 & -2.73 & 11041 & .01 & {$[-.2875,-.0473]$} \\
\hline
\end{tabular}

and confidence intervals. Of the covariates, only the GINI index significantly (positively) predicted structural attributions.

The resulting model supports H1a: higher PSIs are associated with more structural attributions. This significant main effect is qualified by a significant power distance $\times$ PSI interaction effect (H3a supported). The predicted C-PSI $\times$ PSI and individualism $\times$ PSI interaction effects, however, were not significant ( $\mathrm{H} 2 \mathrm{a}$ and $\mathrm{H} 4 \mathrm{a}$ not supported).

\section{Subjective Social Position Predicting Individualist Attributions}

Modelling individualist attributions was done analogously to structural attributions, but with SSP as the individuallevel predictor of interest. Consistent with the moderating hypotheses, SSP was made to interact with individualism, power distance, and C-SSP. PSI was included as an individual-level predictor to account and control for its effects.

The individual-level variance estimate was .35 , while the country-level variance estimate was .07. The latter is significantly different from zero, $\chi^{2}(4)=948.19, p<$ .001 . The intraclass correlation coefficient was .17, that is, $17 \%$ of the variance in individualist attributions is due to country-level variations, specifically, the interactions involving country-level moderators.

Table 6 indicates, for the mixed model, the estimated regression coefficients and their standard errors and confidence intervals. Of the covariates, age, educational attainment, and PSI significantly predicted individualist attributions. More individualist attributions were made by younger persons, more highly educated persons, and persons with higher PSI.

The resulting model supports H1b: higher SSPs are associated with more individualist attributions. This significant main effect is qualified by significant interactions of SSP with C-SSP $(\mathrm{H} 2 \mathrm{~b})$, power distance (H3b), and individualism (H4b).
Simple slopes analyses for multilevel modelling (Preacher, Currant, \& Bauer, 2006) were conducted to determine the nature of the significant cross-level interactions. The regression coefficients reported in Tables 5 and 6 and the coefficients' variance and covariances were encoded in Preacher's (2017) online utilities for probing cross-level, two-way interaction effects in hierarchical linear models. Included in the analysis were the interacting variables and their interaction term. The other individuallevel variables were kept constant at the centered mean of zero; consequently, their interaction terms also became zero.

\section{The Moderating Effects of Power Distance}

Power distance $\times$ PSI interaction. The simple slope of the line with PSI as predictor and structural attributions as outcome is significant and positive for each country (Figure 1, solid line). The slope, however, is higher for countries with smaller power distance. H3a is supported: The effect of PSI on structural attributions is stronger in smaller power-distance countries.

Power distance $\times$ SSP interaction. The simple slope of the line with SSP as predictor and individualist attributions as outcome is significant and positive for countries with smaller power distance (New Zealand, Australia, Japan, Taiwan, and South Korea), but is not significantly different from zero for countries with larger power distance (China and the Philippines; Figure 1, broken line). H3b is supported: The effect of SSP on individualist attributions is stronger in smaller power-distance countries.

\section{The Moderated Effect of SSP on Individualist Attributions}

Individualism $\times$ SSP interaction. The simple slope of the line with SSP as predictor and individualist attributions as outcome is significant and positive for countries with high individualism (Japan, New Zealand, and Australia) but is not significantly different from zero for countries with low individualism (the Philippines, China, South Korea, Taiwan; see Figure 2). H4b is supported: The effect of SSP 


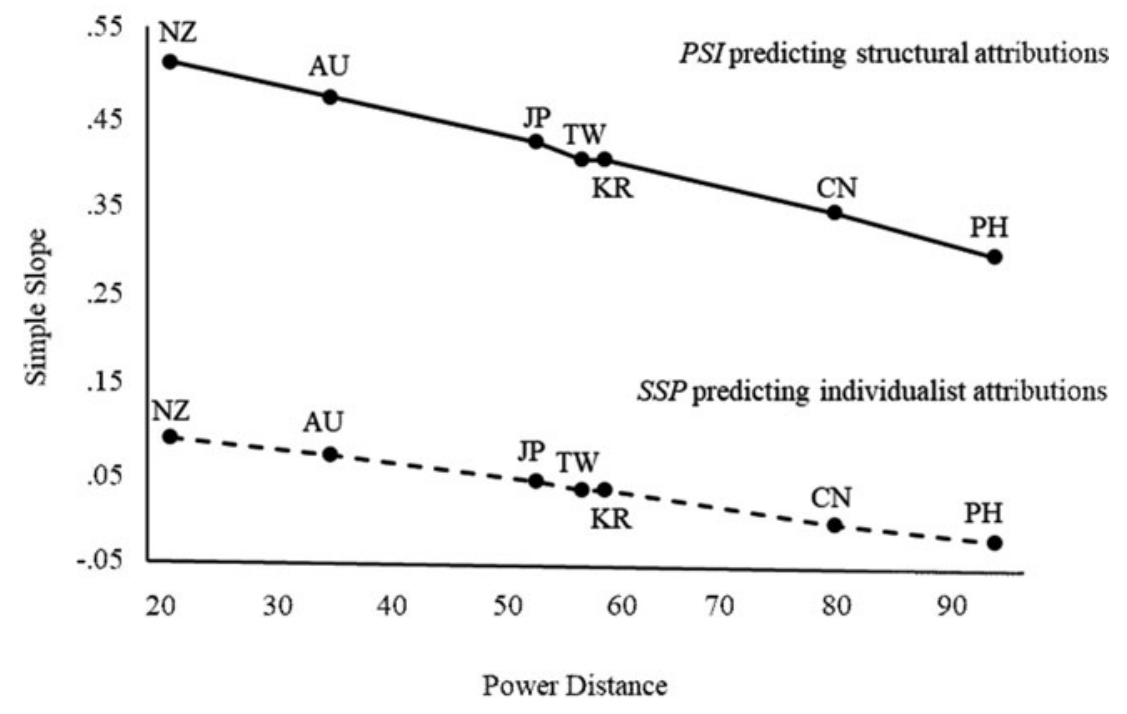

\section{Figure 1}

Simple slopes for different power distances of lines for PSI predicting structural attributions and for SSP predicting individualist attributions.

Note: $\mathrm{AU}=$ Australia, $\mathrm{CN}=$ China, JP = Japan, $\mathrm{KR}=$ Korea, $\mathrm{NZ}=$ New Zealand, $\mathrm{PH}=$ Philippines, TW= Taiwan. SE of slopes for PSI ranges from .02 to .06. SE of slopes for SSP ranges from .01 to .02. Slopes for PSI are all significantly different from zero; slopes for SSP are significantly different from zero except for CN and $\mathrm{PH}$.

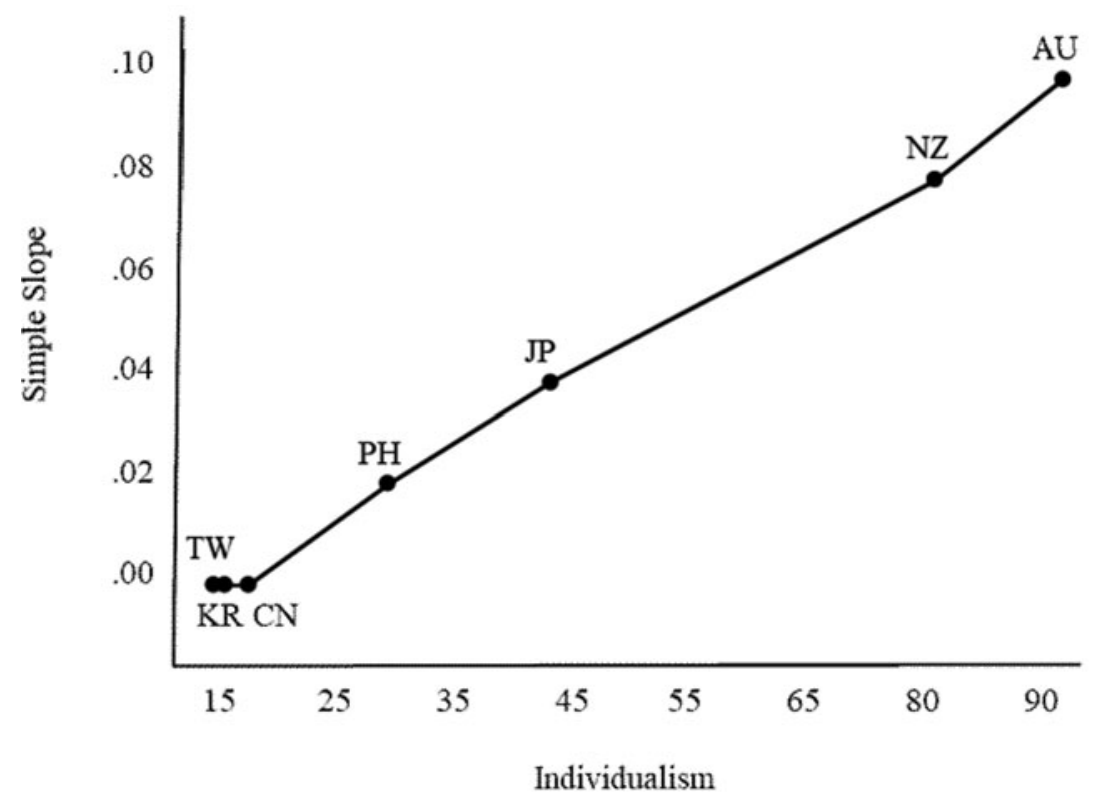

\section{Figure 2}

Simple slopes for different individualism scores of lines for SSP predicting individualist attributions.

Note: $\mathrm{AU}=$ Australia, $\mathrm{CN}=$ China, JP = Japan, $\mathrm{KR}=$ Korea, NZ = New Zealand, PH = Philippines, TW = Taiwan. SE of slopes ranges from .02 to .06. Slopes are significantly different from zero only for JP, NZ, and AU.

on individualist attributions is stronger in individualist countries.

$C$-SSP $\times$ SSP interaction. The simple slope of the line with SSP as predictor and individualist attributions as outcome is significant and positive in countries with lower C-SSP (China, Taiwan, the Philippines, South Korea, and Japan), but is not significantly different from zero in countries with higher C-SSP (Australia, New
Zealand; see Figure 3). H2b is supported: The effect of SSP on individualist attributions is larger in countries with lower C-SSP.

\section{Discussion}

This study's results show that individuals who intensely perceive social inequality tend to attribute mobility to structural or social factors, consistent with the 


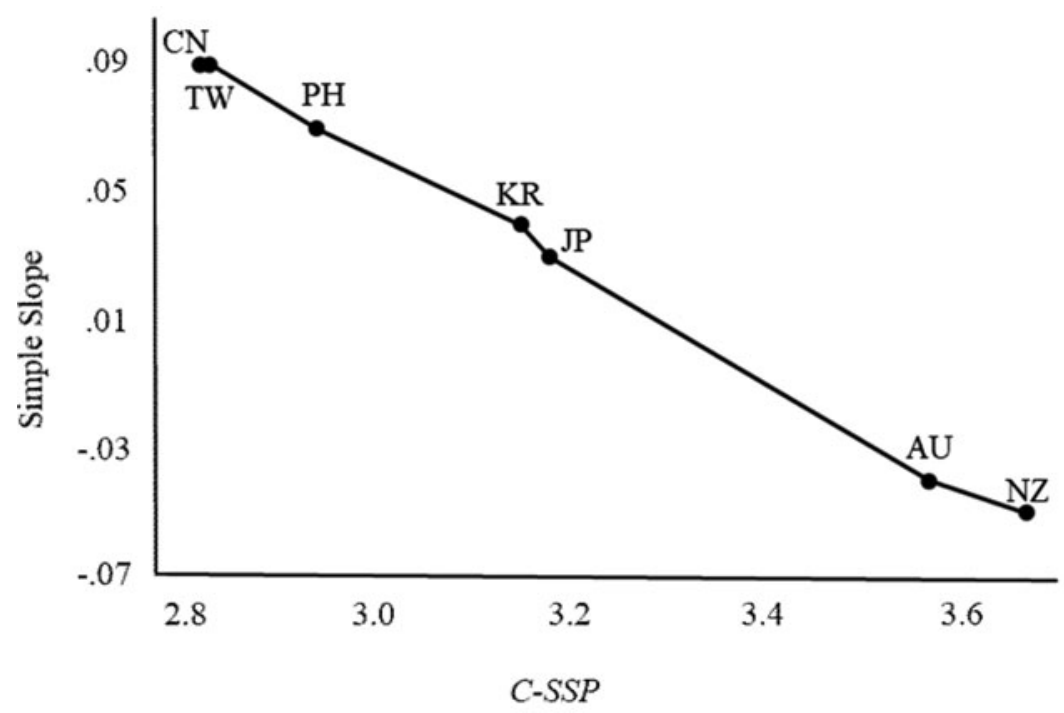

Figure 3

Simple slopes for different C-SSP scores of lines for SSP predicting individualist attributions.

Note: $\mathrm{AU}=$ Australia, $\mathrm{CN}=$ China, JP $=$ Japan, $\mathrm{KR}=$ Korea, $\mathrm{NZ}=$ New Zealand, $\mathrm{PH}=$ Philippines, $\mathrm{TW}=$ Taiwan. $\mathrm{C}-\mathrm{SSP}=$ country average for subjective social position. SE of slopes ranges from .01 to .03. Slopes are significantly different from zero except for AU and NZ.

self-attribution bias of attributing a negative event to factors outside of self. The results also show that individuals who see themselves as highly placed in society tend to attribute mobility to a person's own work, consistent with the self-attribution bias of attributing a positive event to factors within the self. Thus, the ease of social mobility among higher social classes and its difficulty amid inequality facilitate self-attribution bias. Whether individuals' inequality and status perceptions are linked to mobility attributions depends, however, on cultural beliefs. This study shows that the effect of PSI on structural attributions is larger in small power-distance countries, while the effect of SSP on individualist attributions is larger in countries with small power distance, high individualism, and low C-SSP.

The limitations of the current study qualify the validity of its results. First, the Cronbach alphas computed with this study's data were limited (range $=.49-.82 ; M=.66$ ). These values are roughly comparable, however, to those reported in a meta-analysis of Cronbach's alphas, where 297 scales measuring value/belief had a mean alpha of .70 (Peterson, 1994), and in Hunt's (1996) study where a four-item internal scale had a Cronbach's alpha of . 56 and a four-item external scale had a Cronbach's alpha of .65. The scales' small number of items (from two to four) contributed to lowered reliabilities (John \& Benet-Martínez, 2000). The fact that the measures tapped diverse situations also contributed to the lowered reliabilities (Hulin, 2001). For example, structural attributions tapped on race, religion, and gender; PSI tapped on access to education, class conflict, and justness of salaries.

Second, this study needs to be replicated in other regions. The delimited regional scope of this study, however, has the benefit of using a particular cultural context in interpreting the effects of predictors and moderators. Regional studies make it possible to examine the nuances, manifestations, and roots of power distance and individualism that are not evident in general social-cultural frameworks. Beyond replications in different regions, future studies can involve three-level analyses with region, country, and individual, respectively, as the third, second, and first levels.

Third, the respondents gauged attributions not in relation to their own or specific persons' social mobility, but as applied to a country's populace, so that the covariation analysis (Kelley, 1973) triggered by specific events may not have been fully operational. Moreover, the cross-sectional nature of the data precludes establishing whether PSI and SSP temporally precede the attributions made. Temporal sequencing of predictors and outcomes can be guaranteed by a cross-lagged panel design. More specific reference points of social mobility can be incorporated.

\section{Power Distance as a Moderating Context}

It is in small power-distance cultures (Australia and New Zealand) that the positive relationship between PSI and structural attributions is stronger. At the outset, this result appears counterintuitive: large power distance perpetuates inequality and exposes the populace to the entitlements of those in power, thus making them prone to structural attributions. Inequality, however, does not lead to structural attributions in large power-distance cultures because of people's acceptance of power imbalance. It is generally accepted that one must be in a position of power, or gain access to resources of those in power, to advance professionally and socially. In China, for example, job seeking and mobility are seen as a matter of being in the 
opportune location in a segmented labour structure (Lin \& Bian, 1991). Thus, PSI does not stand out as a negative event that would, through self-attribution bias, be linked to structural attributions. This scenario exemplifies the legitimation of inequality even by the disadvantaged (Major, 1994).

It is in small power-distance cultures that entitlement of high-status individuals is deemed unjust and disapproved. While low power-distance countries are more socioeconomically advanced, there could be individuals who feel disadvantaged and sense inequality more intensely and would thus make structural attributions. These individuals can perhaps be likened to those described by Major (1994), who, not feeling responsible for lacking things they want, actually feel entitled to these and thus are more likely to vent anger at external sources. It is important to examine the profiles of these sectors, including their social mobility trends and availment of and reactions to social services.

The positive link between SSP and individualist attributions is also stronger in small power-distance cultures. Thus, there are two mobility attributions in low powerdistance cultures: while those who keenly perceive social inequality make structural attributions, those who identify themselves with higher social classes make individualist attributions. While not providing direct evidence, these contrasting scenarios suggest that disadvantaged groups can, through structural attributions, devalue their competencies for mobility and legitimise any existing inequality. In contrast, the privileged groups can, through individualist attributions, believe themselves deserving of better outcomes and likewise legitimise any existing inequality. Thus, while self-attribution bias has been shown to serve an adaptive function, it can also lead to the acceptance of injustice (Major, 1994) through the differing valuing of advantaged and disadvantaged groups. This study's results suggest that this can happen even in small power-distance countries.

\section{The Context-Dependent Effect of SSP on Individualist Attributions}

While the effect of PSI on structural attributions is not largely context dependent (save for the context of power distance), the effect of SSP on individualist attributions is. The moderating effects of power distance and individualism support the view that high-status peoples' individualist attributions are validated by an egalitarian culture that values hard work to achieve personal goals. The moderating effect of C-SSP supports the view that seeing oneself as high status where the citizenry generally see themselves as low status validates one's individualist attributions.

This study's results suggest that individualist attributions from the vantage point of one's social position is modifiable through societal influences and can be used to enable disadvantaged sectors to achieve social mobility. High-status perceptions beget more individualist attributions in small power-distance contexts, but how could this relationship be replicated in large power-distance contexts? The results of a management simulation study (Eylon \& Au, 1999) showed that empowering individuals by providing them with needed information, giving them responsibility, and increasing their chances for employment made participants from a large power-distance culture work better. A study involving Chinese workplaces (Farh, Hackett, \& Liang, 2007) had a similar result. In large power-distance workplaces, increased levels of perceived organisational support underscored the obligations that workers, to start with, already had towards their employers, resulting in even better work outcomes. While the outcome variables in these studies were work behaviour, there was no counterevidence that a similar effect of empowerment would not be manifested on mobility attributions. These studies suggest how interventions can offset structural disadvantages.

\section{Mobility Attribution Profiles of East Asia and Pacific Cultures}

This study's results indicate that self-attribution bias is neither automatic or universal but is dependent on cultural and country context. There is empirical evidence that self-attribution bias is a Western phenomenon and has little self-serving function in Eastern, collectivist cultures and in Asian cultures where self-promotion is not a norm (Markus \& Kitayama, 1991; Mezulis et al., 2004).

This study yielded profile differences in countries. The profile of Australia and New Zealand is distinct from that of China, the Philippines, Japan, Taiwan, and South Korea. In Australia and New Zealand, the individualist attributions of high-status persons and the structural attributions of persons perceiving social inequality are strengthened; analyses of ISSP data suggest that these are due to their low power-distance and individualist cultures. Australia and New Zealand's high C-SSPs, however, temper the individualist attributions of high-status persons. On the other hand, the acceptance of power imbalance and the focus on the collective in China, the Philippines, Japan, Taiwan, and South Korea, temper the individualist attributions of high-status persons and the structural attributions of persons perceiving social inequality. With low C-SSPs, however, the individualist attributions of high-status persons are strengthened.

Specific manifestations in East Asian workplaces of a large power-distance, collectivist culture provide insight on the diminished relationships between PSI and structural attributions and between SSP and individualist attributions. According to Vinken (2006), East Asian workers are dedicated to the group they work for, ascribing secondary importance to personal rewards and growth. They know that their workplace ensures lifelong security and protection. Social capital is diffused and shared so that structural attributions do not depend much on social inequality. Hard work is not linked to upward mobility as much as it is to group goals, so that individualist attributions do not depend much on social position. 
However, low egalitarianism in these Eastern cultures puts in place a social comparison process for high-status individuals to set themselves apart from the rest and, from this vantage point, assumes that social mobility is a fruit of hard work. East Asian cultures are known for work values characterised by sacrifice, devotion, and perseverance (Vinken, 2006), and these values make individualist attributions culturally available even amid a collectivist culture.

Analysis of the significant power distance $\times$ SSP interaction shows that China and the Philippines, which have the largest power distance, stand out from Japan, Taiwan, and South Korea in that the association between SSP and individualist attributions is not only weak but nonexistent (Figure 1 bottom line). China and the Philippines also have the lowest GDP per capita and the highest GINI index. These figures suggest persistent structural inequality that could markedly constrain individualist attributions of low-status individuals, given objective constraints in their social mobility, and also of high-status individuals, given the entitlements and privileges of their social class. Analysis of the significant individualism $\times$ SSP interaction shows that Japan, which has the highest individualism score, stands out from the rest of the Eastern cultures in that SSP is more strongly associated with individualist attributions (Figure 2). In this regard, Japan is more similar to Australia and New Zealand. This study thus presents a nuanced differentiation among Eastern cultures as a result of structural inequality and rising individualistic values.

\section{Societal Implications of Mobility Attributions}

Mobility attributions research has implications for social and political development (Sahar, 2014). Findings about structural attributions research are relevant to concerns about the legitimisation of power ascribed to sectors with particular sociodemographic, political, or social profiles. Findings about individualist attributions show the extent to which personal agency for social mobility can stand in the face of existing power structures. Knowing whether and how different sectors form different attributional perspectives is relevant to the empowerment of disadvantaged sectors.

The regional profiles presented in this study indicate that even in affluent economies and individualist cultures, sectors that perceive inequality in society or themselves as of low social position make attributions that depreciate their attempts towards mobility. A collectivist culture has a different distinctive feature: while resources and capital tend to be shared and hard work is valued, seeing personal merits as instrumental to one's upward mobility is not central in peoples' minds. Considerations of culture and country contexts, therefore, remain important when working with underprivileged sectors whose skills and competencies need to be harnessed towards upward social mobility (Hardaway \& McLoyd, 2009).

\section{Acknowledgments}

This work was supported by the University Research Coordination Office of De La Salle University. The author wishes to thank Marie Rose H. Morales for assistance in data management.

\section{References}

Billet, P. (2011). Youth social capital: Getting on and getting ahead in life (Doctoral thesis). University of Wollongong, Australia. Retrieved from http://ro.uow.edu.au/theses/3533.

Breen, R. (1997). Inequality, economic growth and social mobility. British Journal of Sociology, 48, 429-449.

Bjørnskov, C., Dreher, A., Fischer, J.A.V., Schnellenbach, J., \& Gehring, K. (2013). Inequality and happiness: When perceived social mobility and economic reality do not match. Journal of Economic Behavior \& Organization, 91, 75-92.

Bochner, S., \& Hesketh, B. (1994). Power distance, individualism/collectivism, and job-related attitudes in a culturally diverse work group. Journal of Cross-Cultural Psychology, 25, 233-257.

Booth, A. (1999). Initial conditions and miraculous growth: Why is South East Asia different from Taiwan and South Korea? World Development, 27, 301-321.

Campbell, J.D., Trapnell, P.D., Heine, S.J., Katz, I.M., Lavallee, L.F., \& Lehman, D.R. (1996). Self-concept clarity: Measurement, personality correlates, and cultural boundaries. Journal of Personality and Social Psychology, 1, 141-156.

Cattell, V. (2001). Poor people, poor places, and poor health: The mediating role of social networks and social capital. Social Science \& Medicine, 52, 1501-1516.

Choi, I., Nisbett, R.E., \& Norenzayan, A. (1999). Causal attribution across cultures: Variation and universality. Psychological Bulletin, 125, 47-63.

Clemente, J.A.R., Daganzo, M.A.A., Bernardo, A.B.I., \& Pangan, C.A.C. (2017). Filipino adolescents' conceptions of socioeconomic mobility: A consensual qualitative research. Child Indicators Research, 10, 117-140.

Duval, T.S., \& Silvia, P.J. (2002). Self-awareness, probability of improvement, and the self-serving bias. Journal of Personality and Social Psychology, 82, 49-61.

Eylon, D., \& Au, K.Y. (1999). Exploring empowerment crosscultural differences along the power distance dimension. International Journal of Intercultural Relations, 23, 373-385.

Farh, J.L., Hackett, R.D., \& Liang, J. (2007). Individual-level cultural values as moderators of perceived organizational support-employee outcome relationships in China: Comparing the effects of power distance and traditionality. Academy of Management Journal, 50, 715-729.

Festinger, L. (1954). A theory of social comparison processes. Human Relations, 7, 117-140.

Fischer, R. (2009). Where is culture in cross cultural research? An outline of a multilevel research process for measuring culture as a shared meaning system. International Journal of Cross Cultural Management, 9, 25-49.

Fong, C. (2001). Social preferences, self-interest, and the demand for redistribution. Journal of Public Economics, 82, 225-246. 
GESIS Leibniz Institute for the Social Sciences (2012). International Social Survey Programme. ISSP 2009-Social Inequality IV. Variable report. Cologne, Germany: Author.

Global Leadership and Organizational Behavior Effectiveness (GLOBE). (2004). Understanding the relationship between national culture, societal effectiveness and desirable leadership attributes: A brief overview of the GLOBE project. Retrieved from http://globeproject.com/study_2004_ 2007\#instruments

Gugushvili, A. (2016). Intergenerational social mobility and popular explanations of poverty: A comparative perspective. Social Justice Research, 29, 402-428.

Gugushvili, A., Bukodi, E., \& Goldthorpe, J.H. (2017). The direct effect of social origins on social mobility chances: 'Glass floors' and 'glass ceilings' in Britain. European Sociological Review, 33, 305-316.

Hardaway, C.R., \& McLoyd, V.C. (2009). Escaping poverty and securing middle class status: How race and socioeconomic status shape mobility prospects for African Americans during the transition to adulthood. Journal of Youth and Adolescence, 38, 242-256.

Hegtvedt, K.A., \& Johnson, C. (2000). Justice beyond the individual: A future with legitimation. Social Psychology Quarterly, 63, 298-311.

Heider, F. (1958). The psychology of interpersonal relations. New York, NY: Wiley.

Hofstede, G. (1983). The cultural relativity of organizational practices and theories. Journal of International Business Studies, 14, 75-89.

Hofstede, G. (2001). Culture's consequences: Comparing values, behaviors, institutions, and organizations across nations (2nd ed.). Thousand Oaks, CA: Sage Publications.

Hofstede, G. (2011). Dimensionalizing cultures: The Hofstede model in context. Online Readings in Psychology and Culture, 2. https://doi.org/10.9707/2307-0919.1014

Hofstede, G., \& Bond, M.H. (1988). The Confucius connection: From cultural roots to economic growth. Organizational $D y$ namics, 16, 5-21.

Hofstede, G., Hofstede, G.J., \& Minkov, M. (2010). Cultures and organizations: Software of the mind. (3rd ed.). New York: McGraw-Hill.

Hong, Y.Y., Morris, M.W., Chiu, C.Y., \& Benet-Martinez, V. (2000). Multicultural minds: A dynamic constructivist approach to culture and cognition. American Psychologist, 55, 709-720. doi:10.1037//0003-066X.55.7.70

Hulin, C. (2001). Measurement. III.B. Can a reliability coefficient be too high? Journal of Consumer Psychology, 10, 55-56.

Hunt, M.O. (1996). The individual, society, or both? A comparison of black, Latino, and white beliefs about the causes of poverty. Social Forces, 75, 293-322.

International Social Survey Programme (ISSP). (2008). International Social Programme 2009 Social Inequality IV. Final questionnaire. Retrieved from https://www.gesis.org/issp/ modules/issp-modules-by-topic/social-inequality/2009/

International Social Survey Programme (ISSP) Research Group. (2012). International Social Survey Programme: Social In- equality IV - ISSP 2009. Cologne, Germany: GESIS Data Archive, Cologne. ZA5400 Data file version 3.0.0. doi:10.4232/1.11506

Kim, S. (2010). Public trust in government in Japan and South Korea: Does the rise of critical citizens matter? Public Administration Review, 70, 801-810.

Kluegel, J.R. (1987). Macro-economic problems, beliefs about the poor and attitudes toward welfare spending. Social Problems, 33, 82-99.

Kraus, M.W., Piff, P.K., \& Keltner, D. (2009). Social class, sense of control, and social explanation. Journal of Personality and Social Psychology, 97, 992-1004. doi:10.1037/a0016357

John, O.P., \& Benet-Martínez (2000). Measurement: Reliability, construct validation, and scale construction. In H.T. Reis \& C.M. Judd (Eds.), Handbook of research methods in social and personality psychology (pp. 339-369). New York, NY: Cambridge University Press.

Johnson, T., Kulesa, P., Cho, Y.I., \& Shavitt, S. (2005). The relation between culture and response styles. Evidence from 19 countries. Journal of Cross-Cultural Psychology, 36, 264-277. doi:10.1177/0022022104272905

Kelley, H.H. (1973). The processes of causal attribution. American Psychologist, 28, 107-128.

Kelley, H.H., \& Michela, J.L. (1980). Attribution theory and research. Annual Review of Psychology, 31, 457-501.

Kerr, W.R. (2014). Income inequality and social preferences for redistribution and compensation differentials. Journal of Monetary Economics, 66, 62-78.

Letki, N., \& Mierina, I. (2015). Getting support in polarized societies: Income, social networks, and socioeconomic context. Social Science Research, 49, 217-233.

Lew, J. (2010). Asian American youth in poverty: Benefits and limitations of ethnic networks in postsecondary and labor force options. Journal of Education for Students Placed at Risk, $15,127-143$.

Lin, N., \& Bian, Y. (1991). Getting ahead in urban China. American Journal of Sociology, 657-688.

Major, B. (1994). From social inequality to personal entitlement: The role of social comparisons, legitimacy appraisals, and group membership. Advances in Experimental Social Psychology, 26, 293-355.

Markus, H.R., \& Kitayama, S. (1991). Culture and the self: Implications for cognition, emotion, and motivation. Psychological Review, 98, 224-253.

Matsumoto, D., Yoo, S.H., Fontaine, J., Anguas-Wong, A.M., Arriola, M., Ataca, B., ... Grossi, E. (2008). Mapping expressive differences around the world: The relationship between emotional display rules and individualism versus collectivism. Journal of Cross-Cultural Psychology, 39, 55-74. doi:10.1177/0022022107311854

Mead, G.H. (1934). Mind, self, and society. Chicago: University of Chicago Press.

Mezulis, A.H., Abramson, L.Y., Hyde, J.S., \& Hankin, B.L. (2004). Is there a universal positivity bias in attributions? A metaanalytic review of individual, developmental, and cultural 
differences in the self-serving attributional bias. Psychological Bulletin, 130, 711-747. doi:10.1037/0033-2909.130.5.711

Moghaddam, F.M. (2003). Interobjectivity and culture. Culture \& Psychology, 9, 221-232.

Moghaddam, F.M. (2010). Commentary: Intersubjectivity, interobjectivity, and the embryonic fallacy in developmental science. Culture \& Psychology, 16, 465-475. doi:10.1177/1354067X10380160

Montiel, C.J., \& Macapagal, M.E.J. (2006). Effects of social position on societal attributions of an asymmetric conflict. Journal of Peace Research, 43, 219-227.

Morris, M.W., \& Peng, K. (1994). Culture and cause: American and Chinese attributions for social and physical events. Journal of Personality and Social Psychology, 67, 949-971.

NationMaster (2017). Economy >Distribution of family income > Gini index: Countries compared. Retrieved from http://www.nationmaster.com/country-info/stats/ Economy/Distribution-of-family-income/Gini-index

Neckerman, K.M., \& Torche, F. (2007). Inequality: Causes and consequences. Annual Review of Sociology, 33, 335-357.

Orr, L.M., \& Hauser, W.J. (2008). A re-inquiry of Hofstede's cultural dimensions: A call for 21st century cross-cultural research. The Marketing Management Journal, 18, 1-19.

Oyserman, D., Coon, H.M., Kemmelmeier, M. (2002). Rethinking individualism and collectivism: Evaluation of theoretical assumptions and meta-analyses. Psychological Bulletin, 128, $3-72$.

Perry, B. (2013). What do we know about income inequality in NZ? Extracts from the 2013 household income reports. Retrieved from http://igps.victoria.ac.nz/events/ Inequity\%20Forum/InequalitySummary_Bryan_Perry_ 2013HIR.pdf

Peterson, R.A. (1994). A meta-analysis of Cronbach's coefficient alpha. Journal of Consumer Research, 21, 381-391.

Preacher, K.J. (2017). Interactive calculation tools for establishing simple intercepts, simple slopes, and regions of significance. Retrieved from http://quantpsy.org/interact/index.htm

Preacher, K.J., Curran, P.J., \& Bauer, D.J. (2006). Computational tools for probing interactions in multiple linear regression, multilevel modeling, and latent curve analyses. Journal of Educational and Behavioral Statistics, 41, 437-448.

Putnam, R.D. (1993). The prosperous community. The American Prospect, 4, 35-42.

Raudenbush, S.W., \& Bryk, A.S. (2002). Advanced quantitative techniques in the social sciences series: Vol. 1. Hierarchical linear models. Applications and data analysis methods (2nd ed.). Thousand Oaks, CA: Sage.

Republic of China (Taiwan) Statistical Bureau (2017). Republic of China (Taiwan) statistics from Statistical Bureau. Retrieved from http://eng.stat.gov.tw/ct.asp?xItem= $37408 \&$ CtNode $=5347 \& \mathrm{mp}=5$

Robert, C., Probst, T.M., Martocchio, J.J., Drasgow, F., \& Lawler, J.J. (2000). Empowerment and continuous improvement in the United States, Mexico, Poland, and India: Fit on the basis of the dimensions of power distance and individualism. Journal of Applied Psychology, 85, 643-658.
Russell, G.M. (1996). Internalized classism: The role of class in the development of self. Women \& Therapy, 18, 59-71.

Sachweh, P. (2012). The moral economy of inequality: Popular views on income differentiation, poverty and wealth. SocioEconomic Review, 10, 419-445. doi:10.1093/ser/mwr023

Saguy, T., \& Chernyak-Hai, L. (2012). Intergroup contact can undermine disadvantaged group members' attributions to discrimination. Journal of Experimental Social Psychology, 48, 714-720. doi:10.1016/j.jesp.2012.01.003

Sahar, G. (2014). On the importance of attribution theory in political psychology. Social and Personality Psychology Compass, 8, 229-249.

Sakamoto, A., Rarick, J., Woo, H., \& Wang, S.X. (2014). What underlies the Great Gatsby Curve? Psychological microfoundations of the 'vicious circle' of poverty. Mind \& Society, 13, 195-211. doi: 10.1007/s11299-014-0144-x

Schimmack, U., Oishi, S., \& Diener, E. (2005). Individualism: A valid and important dimension of cultural differences between nations. Personality and Social Psychology Review, 9, $17-31$.

Shane, J., \& Heckhausen, J. (2013). University students' causal conceptions about social mobility: Diverging pathways for believers in personal merit and luck. Journal of Vocational Behavior, 82, 10-19.

Taras, V., Kirkman, B.L., \& Steel, P. (2010). Examining the impact of Culture's consequences: A three-decade, multilevel, metaanalytic review of Hofstede's cultural value dimensions. Journal of Applied Psychology, 95, 405.

Taylor, M.C., \& Merino, S.M. (2011). Race, religion, and beliefs about racial inequality. The Annals of the American Academy of Political and Social Science, 634, 60-77. doi:10.1177/0002716210389537

Triandis, H.C. (1989). The self and social behavior in differing cultural contexts. Psychological Review, 96, 506-520.

Tsukamoto, S., Holland, E., Haslam, N., Karasawa, M., \& Kashima, Y. (2015). Cultural differences in perceived coherence of the self and ingroup: A Japan-Australia comparison. Asian Journal of Social Psychology, 18, 83-89.

Vinken, H. (2006). East Asian Values Surveys. Making a case for East Asian-origin values survey concepts. Mannheim: ZUMA (ZUMA Arbeitsbericht 2006/05).

Weiner, B. (2008). Reflections on the history of attribution theory and research: People, personalities, publications, problems. Social Psychology, 39, 151-156.

Weiner, B., Osborne, D., \& Rudolph, U. (2010). An attributional analysis of reactions to poverty: The political ideology of the giver and the perceived morality of the receiver. Personality and Social Psychology Review, 15, 199-213. doi: $10.1177 / 1088868310387615$

The World Bank. (2017). The World Bank national accounts data and OECD national accounts data files. Retrieved from https://data.worldbank.org/indicator/NY.GDP.PCAP.CD? view $=$ chart

Yun, Y.M. (1994). Class structure and class mobility in East Asia: A comparison among South Korea, Japan and Taiwan. Korea Journal of Population and Development, 23, 258-282. 